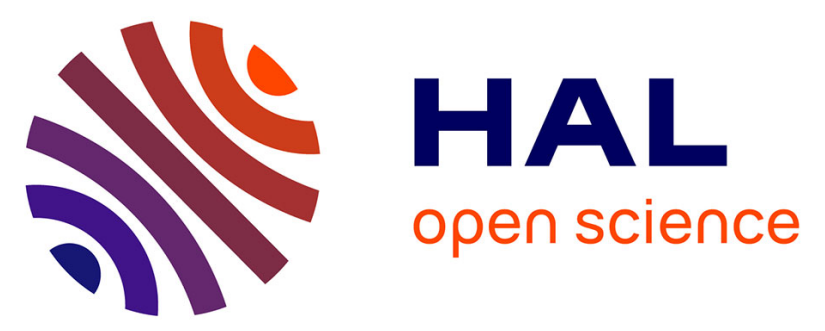

\title{
Steam gasification of char from wood chips fast pyrolysis: Development of a semi-empirical model for a fluidized bed reactor application
}

\author{
S. Septien, Francisco Javier Escudero Sanz, Sylvain Salvador, S. Valin
}

\section{- To cite this version:}

S. Septien, Francisco Javier Escudero Sanz, Sylvain Salvador, S. Valin. Steam gasification of char from wood chips fast pyrolysis: Development of a semi-empirical model for a fluidized bed reactor application. Biomass and Bioenergy, 2015, 77, pp.64-74. 10.1016/j.biombioe.2015.03.011. hal02088596

\section{HAL Id: hal-02088596 \\ https://imt-mines-albi.hal.science/hal-02088596}

Submitted on 5 Apr 2019

HAL is a multi-disciplinary open access archive for the deposit and dissemination of scientific research documents, whether they are published or not. The documents may come from teaching and research institutions in France or abroad, or from public or private research centers.
L'archive ouverte pluridisciplinaire HAL, est destinée au dépôt et à la diffusion de documents scientifiques de niveau recherche, publiés ou non, émanant des établissements d'enseignement et de recherche français ou étrangers, des laboratoires publics ou privés. 


\title{
Steam gasification of char from wood chips fast pyrolysis: Development of a semi-empirical model for a fluidized bed reactor application
}

\author{
S. Septien ${ }^{a}$, F.J. Escudero Sanz ${ }^{a, *}$, S. Salvador ${ }^{a}$, S. Valin ${ }^{b}$ \\ a Mines - Albi, RAPSODEE, CNRS UMR 5302, Campus Jarlard, 81000 Albi, France \\ ${ }^{\mathrm{b}}$ CEA, LITEN, 38054 Grenoble Cedex 9, France
}

\begin{abstract}
A B S T R A C T
This study, performed in the context of GAYA project, focuses on the development of a simple predictive model about steam gasification of char from woodchips fast pyrolysis. A semi-empirical model was developed through experiments in a macro thermogravimetric analyzer which owns the peculiar ability of fast heating, as well as to deal with macro-size particles and higher mass loads compared to conventional TGA. The experimental results show that gasification is controlled by chemical kinetics and internal transfer phenomena. During gasification, char particles can be considered as isothermal in a given range of temperatures and particle sizes, more likely for low values. The gasification model was based on the effectiveness factor, which involves the chemical kinetics and diffusion rate. The chemical kinetics were expressed by a classical Arrhenius law, whereas empirical expressions from mathematical fitting of the experimental data were established for the diffusion coefficient and surface function. The diffusion coefficient from this work is suspected to probably include supplementary rate limiting phenomena, apart from steam porous diffusion, such as $\mathrm{H}_{2}$ inhibition and/or the decrease of temperature within char particles because of the endothermic character of gasification. The model globally predicts with accuracy the gasification rate in typical operating conditions of a fluidized bed reactor. For its simplicity and reliability, this approach can be used for the modelling of char gasification in the conditions of interest.
\end{abstract}

\section{Keywords:}

Fluidized bed reactor

Woodchips

Char gasification

Thermogravimetry

Modelling

Effectiveness factor

\section{Introduction}

Biomass gasification is a process with a high potential for energetic transition, as it represents a sustainable alternative for fossil fuels with low greenhouse gas emission. Through this process, biomass is decomposed into a gas mixture, mainly composed of $\mathrm{H}_{2}$ and $\mathrm{CO}$, due to the action of heat and chemical reagents such as $\mathrm{H}_{2} \mathrm{O}, \mathrm{CO}_{2}$ or $\mathrm{O}_{2}$ in stoichiometric default. The gas produced by gasification has many energetic applications, as the synthesis of biomethane that can be used as fuel for transportation and power generation.

The GAYA Project aims to demonstrate the industrial, technical and economic feasibility of biomethane production

\footnotetext{
* Corresponding author. Tel.: +33 (0)563 493275.

E-mail addresses: santiago.septien@hotmail.com (S. Septien), javier.escuderosanz@mines-albi.fr (F.J. Escudero Sanz).
} 


\begin{tabular}{|c|c|}
\hline \multicolumn{2}{|c|}{ Nomenclature } \\
\hline $\mathrm{C}_{\mathrm{H} 2 \mathrm{O}}$ & steam concentration, $\mathrm{mol} \cdot \mathrm{m}^{-3}$ \\
\hline $\mathrm{D}$ & diffusion coefficient, $\mathrm{m}^{2} \cdot \mathrm{s}^{-1}$ \\
\hline$D_{k}$ & Knusden diffusion coefficient, $\mathrm{m}^{2} \cdot \mathrm{s}^{-1}$ \\
\hline$D_{m}$ & molecular diffusion coefficient, $\mathrm{m}^{2} \cdot \mathrm{s}^{-1}$ \\
\hline$E_{a}$ & activation energy $\mathrm{J} \cdot \mathrm{mol}^{-1}$ \\
\hline$f(X)$ & surface function \\
\hline$k_{0}$ & pre-exponential factor $\mathrm{Pa}^{-\mathrm{n}} \cdot \mathrm{s}^{-1}$ \\
\hline$k_{\text {int }}$ & chemical kinetics constant, $\mathrm{s}^{-1}$ \\
\hline$M_{\text {char }}$ & char molecular weight, $\mathrm{kg} \cdot \mathrm{mol}^{-1}$ \\
\hline $\mathrm{M}_{\mathrm{H} 2 \mathrm{O}}$ & water molecular weight, $\mathrm{kg} \cdot \mathrm{mol}^{-1}$ \\
\hline $\mathrm{M}_{\mathrm{N} 2}$ & nitrogen molecular weight, $\mathrm{kg} \cdot \mathrm{mol}^{-1}$ \\
\hline$L_{c}$ & characteristic length, $\mathrm{m}$ \\
\hline$m(t)$ & sample mass, $g$ \\
\hline$m_{0}$ & initial mass sample, $g$ \\
\hline$n$ & order of the reaction \\
\hline$P_{t}$ & total pressure, $\mathrm{Pa}$ \\
\hline$P_{\mathrm{H} 2 \mathrm{O}}$ & steam partial pressure, $\mathrm{Pa}$ \\
\hline $\mathrm{R}$ & ideal gas constant, $\mathrm{J}^{-1} \cdot \mathrm{mol}^{-1} \cdot \mathrm{K}^{-1}$ \\
\hline$R_{\text {ref }}$ & reference reactivity, $\mathrm{s}^{-1}$ \\
\hline \multicolumn{2}{|c|}{$R(t)$ or $R(X)$ reactivity, $s^{-1}$} \\
\hline$r_{a p p}$ & apparent reaction rate, $\mathrm{mol} \cdot \mathrm{m}^{-3} \cdot \mathrm{s}^{-1}$ \\
\hline$r_{D}$ & diffusion rate, $\mathrm{mol} \cdot \mathrm{m}^{-3} \cdot \mathrm{s}^{-1}$ \\
\hline & intrinsic reaction rate, $\mathrm{mol} \cdot \mathrm{m}^{-3} \cdot \mathrm{s}^{-1}$ \\
\hline & mean pore radius, $\mathrm{m}$ \\
\hline & specific surface area, $\mathrm{m}^{2} \cdot \mathrm{kg}^{-1}$ \\
\hline & temperature, $\mathrm{K}$ \\
\hline \multicolumn{2}{|c|}{$X$ or $X(t)$ conversion } \\
\hline$x$ & thickness, $\mathrm{m}$ \\
\hline \multicolumn{2}{|c|}{ Greek nomenclature } \\
\hline$\varepsilon$ & porosity \\
\hline$\eta$ & efficiency \\
\hline$\Phi$ & Thiele modulus \\
\hline$\rho_{\text {app }}$ & apparent density, $\mathrm{kg} \cdot \mathrm{m}^{-3}$ \\
\hline$\rho_{\text {bulk }}$ & bulk density, $\mathrm{kg} \cdot \mathrm{m}^{-3}$ \\
\hline$(\Sigma \Upsilon)_{\mathrm{H} 2 \mathrm{O}}$ & steam diffusion volume \\
\hline$(\Sigma r)_{\mathrm{N} 2}$ & nitrogen diffusion volume \\
\hline$\tau$ & tortuosity \\
\hline \multicolumn{2}{|c|}{ Abbreviations } \\
\hline $\mathrm{CO}$ & carbon monoxide \\
\hline $\mathrm{CO}_{2}$ & carbon dioxide \\
\hline FBR & fluidized bed reactor \\
\hline $\mathrm{H}_{2}$ & hydrogen \\
\hline $\mathrm{H}_{2} \mathrm{O}$ & steam \\
\hline TGA & thermogravimetric analyzer \\
\hline
\end{tabular}

by biomass gasification in France. The technology selected, a fast internally circulating fluidized bed reactor, couples a bubbling fluidized bed reactor (FBR) for gasification and a transported bed reactor for combustion. In the gasifier, the biomass is pyrolyzed in an atmosphere composed of steam, resulting in the production of gas ( $70 \%$ mass fraction), tar ( $15 \%$ mass fraction) and char ( $15 \%$ mass fraction). The pyrolysis products subsequently react among them and/or with the steam present in the atmosphere. The char is partially gasified during its residence in the gasifier. In the combustor, the oxidation of the remaining char provides the required heat for biomass thermochemical conversion in the gasifier which is globally endothermic.

The char residence time in the gasifier needs to be optimised in order to simultaneously maximize the syngas production through char steam gasification and leave enough residual solid for burning in the combustor to keep autothermicity. The control of char residence time in the gasifier is then a key parameter of the process. For this purpose, the understanding of char gasification kinetics on the conditions of interest and the development of a predictive model is essential. The gasification model should then be integrated into a reactor model which describes biomass decomposition in a FBR. Noubli et al. [1] describes the modelling approach selected for the reactor model.

Major part of the studies about char gasification in literature focuses on chemical kinetics, neglecting heat and mass transfer phenomena. Chemical kinetics is typically determined with experiments in a thermogravimetric analyzer (TGA), which enables to work on controlled conditions. Nevertheless, in industrial FBR, biomass feedstock usually consists of large particles: char gasification may then be limited by heat and mass transfer phenomena. Literature about macrosized char particles gasification, which is much less abundant in comparison to intrinsic kinetic studies, puts into evidence the limitation by transfer phenomena. Globally, a decrease of gasification rate is observed by increasing the char particle size. The critical char size from which transfers become limiting depends on the chemical and physical characteristics of the fuel, as well as on the reactor operating conditions. In the case of spherical wood char, several works agree that this critical size is located in the scale of the millimeter [2-4] in the temperature range of $800-1000{ }^{\circ} \mathrm{C}$. A critical size in the same order of magnitude has been found for char from woodchips by Van de Steene et al. [5].

In order to describe the gasification of large char particles, several models considering chemical kinetics and transfer phenomena have been developed, either structural or volumetric [5-10]. These models describe the local changes in internal structure with conversion, notably pore development, but require too high computing capacities to be integrated in a reactor model. On the other hand, several studies have used analytical and semi-analytical approaches in order to simplify char gasification modelling. These approaches attempt to capture the main chemical and physical phenomena in a way as simple as possible [11-15]. Other authors have employed simple empirical correlations, as Standish et al. [16] who have included the initial particle size, raised to a power of 0.81 , in an $n^{\text {th }}$ order apparent kinetic expression. Teixeira et al. [17] developed an empirical correlation of conversion rate as a function of the operating conditions, namely temperature and reagent partial pressure, and char particle characteristics, namely size, porosity and pre-exponential factor.

More information about large char particles gasification models is provided in an extensive review by Gomez-Barea [18].

The objective of the present work, performed in the context of GAYA project, is to characterize and model steam gasification of large char particles. The char gasification model 
will be integrated into a reactor model among other submodels, in a similar way as described in the work of Kramb et al. [19]. The gasification model should be predictive and as simple as possible in order to limit the complexity of the final reactor model.

For this purpose, thermogravimetry experiments were performed in a macro TGA with char samples of different sizes, prepared from woodchips fast pyrolysis. Woodchips were chosen for this study, as they are representative feedstock in industrial fluidized beds. This differs from what is usually studied in literature, namely a spherical geometry. Fast pyrolysis was selected as the most propitious way to reproduce char formation conditions in a FBR where the global heat transfer coefficients are high, commonly estimated to be in the order of $100 \mathrm{~W} \cdot \mathrm{m}^{-2} \cdot \mathrm{K}^{-1}[20-22]$.

\section{Materials and methods}

\subsection{Description of the woodchips}

Char samples were prepared from fast pyrolysis of beech woodchips, which is one of the most preferable feedstock in GAYA project. The woodchips, provided from a French forestry cooperative, are issued from forests located in the middle of France. The woodchips were stored in closed room for several months before use.

The composition analysis of wood, provided by the supplier, is found in Table 1 . The size of the woodchips is very heterogeneous, with the width and length varying from some $\mathrm{mm}$ to a few $\mathrm{cm}$, and the thickness varying from some $0.1 \mathrm{~mm}$ to a few $\mathrm{mm}$.

\subsection{Description of the macro TGA}

The experimental work was based on experiments in a homemade Macro TGA. The concept of this device is similar to that of a conventional TGA, i.e. an online measurement of the mass sample during the transformation. Two main features distinguish this experimental facility:

- The sample is not heated at the same time as the furnace. In fact, it is rapidly introduced into the heated zone of the reactor, already at the set temperature. Thereby, the heating fluxes in this device are high;

- The device can accept large particles and higher mass loads.

Fig. 1 displays a scheme of the macro TGA. The furnace consists of a vertical alumina tube of $75 \mathrm{~mm}$ in internal diameter and $1.2 \mathrm{~m}$ in height, heated by an electric furnace.
The carrier gas is preheated and introduced at the top of the reactor, from where it flows towards the bottom.

The sample is contained in a platinum crucible, fixed to an alumina support which can be introduced at different heights of the reactor by the means of a manual crank handle. The walls of the crucible consist in a grid which offers an easy evacuation to the gas. This minimizes the risk of a gas stagnant layer formation in the crucible, which can lead to external transfer limitations [23]. The crucible and its supports stand on a $0.1 \mathrm{mg}$ precision balance linked to a computer which records the mass evolution as a function of time.

The introduction of the sample into the reaction zone at the target temperature takes some seconds.

\subsection{Preparation of char samples}

The char particles were prepared from the woodchips pyrolysis in the macro TGA device. In this apparatus, the sample is rapidly introduced into the heated zone of the reactor where the heating rate is estimated to be in the order of $100 \mathrm{~W} \cdot \mathrm{m}^{2} \cdot \mathrm{K}^{-1}$ or $100 \mathrm{~K} \cdot \mathrm{s}^{-1}$ [24]. Pyrolysis in the macro TGA was performed at $850{ }^{\circ} \mathrm{C}$, which is the $\mathrm{FBR}$ operation temperature considered in Gaya project, under an inert $\mathrm{N}_{2}$ stream flowing around the sample at a velocity of $0.2 \mathrm{~m} \cdot \mathrm{s}^{-1}$

Woodchips with regular parallelepiped shape were selected for pyrolysis. The shrinking factor, calculated as the ratio between thickness after and before pyrolysis, is similar for the different particle sizes, and corresponds to approximately 0.6. The char yield was comprised between 0.12 and $0.15 \mathrm{~g} \cdot \mathrm{kg}^{-1}$ of dry biomass, depending on the particle size. In fact, the char yield tends to decrease by decreasing the particle size. This classical result can be attributed to higher internal heating rates for the smaller particles, as it is well known that higher heating rates lead to lower char yields. The char samples were classified by thickness, which is the representative dimension with respect to gasification reaction rate for char from woodchips, as demonstrated by Van de Steene et al. [5]. Table 2 shows, for each sample group, the char dimensions and the thickness of the corresponding woodchips.

For each pyrolysis batch, the crucible is loaded as full as possible with woodchips of the same thickness range, while considering that there has to be enough space between particles in order to avoid contact. The mass load depends on the wood particle size. For the smallest particles, around $150 \mathrm{mg}$ of woodchips can be placed on the crucible, while for the largest ones the load can go up to $4 \mathrm{~g}$. The crucible is then placed in the heated zone of the macro TGA and maintained there until the mass is completely stabilized, i.e. during approximatively $8 \mathrm{~min}$.
Table 1 - Composition analysis of wood chips.

\begin{tabular}{lccccc} 
Moisture mass fraction (\%) & Ash dry mass fraction (\%) & \multicolumn{4}{c}{ Ultimate analysis (m.a.f) element mass fraction (\%) } \\
\cline { 2 - 5 } & & C & H & O & N \\
\hline 7 & 0.5 & 49.4 & 5.7 & 44.5 & 0.3 \\
\hline
\end{tabular}




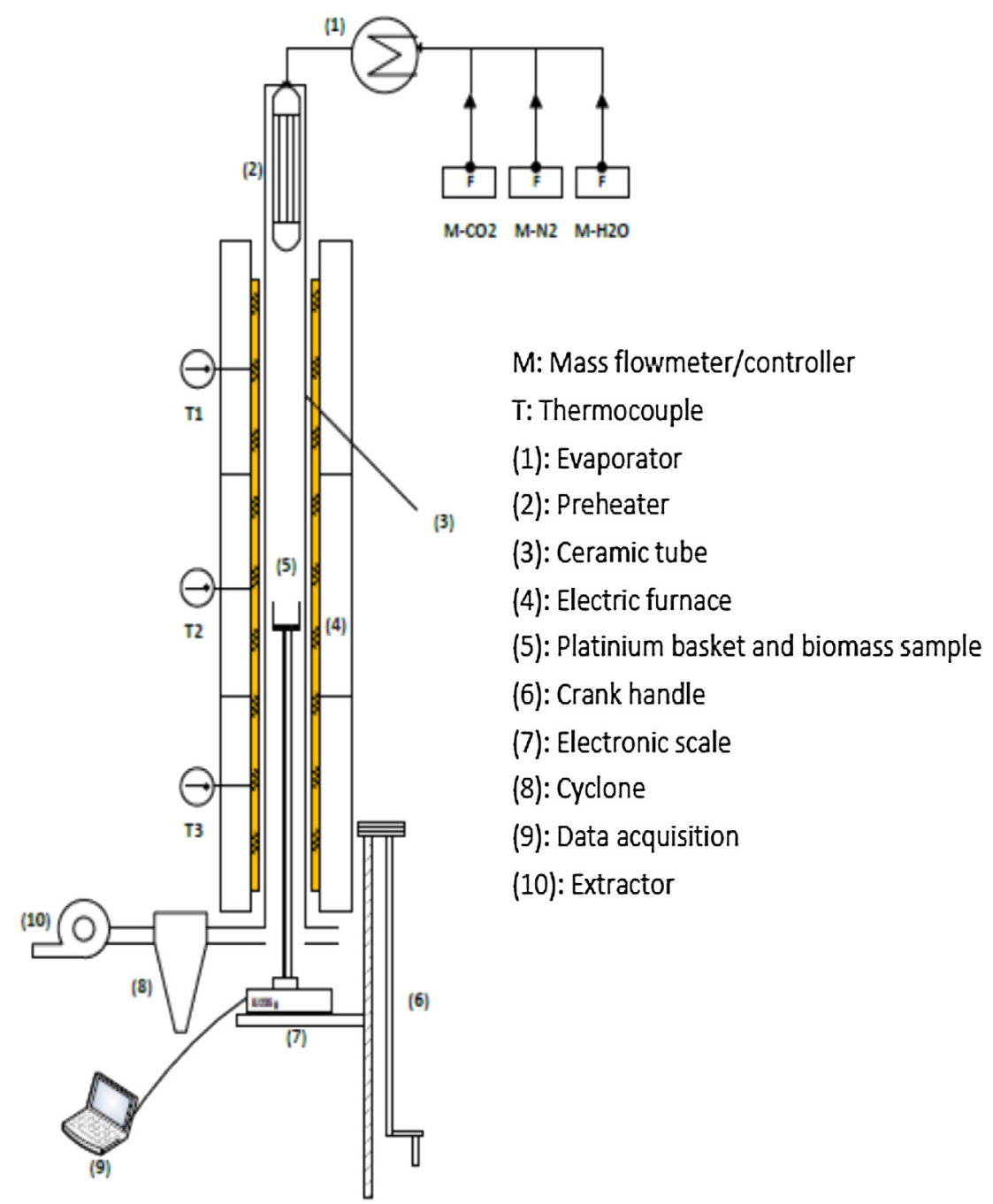

Fig. 1 - Scheme of the macro TGA facility.

\subsection{Gasification experiments}

Gasification experiments were performed in the macro TGA. Firstly, the crucible is loaded with char from the same sample group so as to avoid contact between particles. The mass load can vary from 0.1 to $0.5 \mathrm{~g}$, depending on the char sample. The introduction of the sample into the reactor is performed under an inert $\mathrm{N}_{2}$ atmosphere. After the stabilization of the mass sample, which can take several minutes, the atmosphere is turned into a mixture of steam and $\mathrm{N}_{2}$. Once the sample mass stops to decrease, the sample is removed from the reactor. At this stage, only ash remains on the crucible. A gasification run can last from an hour to $10 \mathrm{~min}$, depending on the sample and the experimental conditions.

The operating conditions to test were the temperature between 750 and $950^{\circ} \mathrm{C}$-, the steam concentration - between 15 and $50 \%$ mole fraction -, and the velocity of the carrier gas -0.2 and $0.4 \mathrm{~m} \cdot \mathrm{s}^{-1}$. For one of the experiments, a small $\mathrm{H}_{2}$ mole fraction of $4 \%$ was introduced into the gasification atmosphere. A couple of experiments were conducted under air.

Gasification experiments were performed with samples in their raw form to determine apparent kinetics or as a powder

Table 2 - Char samples groups segregated by particle thickness.

\begin{tabular}{|c|c|c|c|c|c|c|}
\hline \multirow[t]{2}{*}{ Sample reference } & \multirow{2}{*}{$\begin{array}{l}\text { Wood chips thickness } \\
\text { (mm) }\end{array}$} & \multicolumn{3}{|c|}{ Char dimensions (mm) } & \multirow{2}{*}{$\begin{array}{l}\text { Mean char thickness } \\
\text { (mm) }\end{array}$} & \multirow{2}{*}{$\begin{array}{l}\text { Characteristic length } \\
(\mathrm{mm})\end{array}$} \\
\hline & & Thickness & Length & Width & & \\
\hline $0.6 \mathrm{~mm}$ & $0.5-1.5$ & $0.3-0.9$ & $4-12$ & $2-6$ & 0.7 & $0.27 \pm 0.01$ \\
\hline $1.2 \mathrm{~mm}$ & $1.5-2.5$ & $0.9-1.5$ & - & - & 1.3 & - \\
\hline $1.8 \mathrm{~mm}$ & $2.5-3.5$ & $1.5-2.1$ & $10-17$ & $4-13$ & 1.8 & $0.66 \pm 0.01$ \\
\hline $2.4 \mathrm{~mm}$ & $3.5-4.5$ & $2.1-2.7$ & - & - & 2.3 & - \\
\hline $3.0 \mathrm{~mm}$ & $4.5-5.5$ & $2.7-3.3$ & $15-25$ & $4-17$ & 2.8 & $0.93 \pm 0.12$ \\
\hline
\end{tabular}


Table 3 - Reactivities, Thiele modulus and efficiencies for all the experiments.

\begin{tabular}{|c|c|c|c|c|c|c|c|c|}
\hline \multicolumn{4}{|l|}{ Experiment } & \multicolumn{3}{|c|}{ Reference reactivity $\left(\min ^{-1}\right)$} & \multirow{2}{*}{$\frac{\text { Thiele modulus }}{\text { Model }}$} & \multirow{2}{*}{$\frac{\text { Efficiency }}{\text { Model }}$} \\
\hline Sample & $\mathrm{T}\left({ }^{\circ} \mathrm{C}\right)$ & $\% \mathrm{H}_{2} \mathrm{O}$ & $\mathrm{U}_{\mathrm{g}}\left(\mathrm{m} \cdot \mathrm{s}^{-1}\right)$ & $\operatorname{Exp}$ & Model & Deviation & & \\
\hline Ground $1.8 \mathrm{~mm}$ & 750 & 35 & 0.2 & $0.045 \pm 0.012$ & 0.046 & $2 \%$ & $<0.3$ & 1.00 \\
\hline Ground $1.8 \mathrm{~mm}$ & 780 & 15 & 0.2 & $0.076 \pm 0.020$ & 0.066 & $13 \%$ & $<0.3$ & 1.00 \\
\hline Ground $1.8 \mathrm{~mm}$ & 780 & 25 & 0.2 & $0.10 \pm 0.03$ & 0.092 & $8 \%$ & $<0.3$ & 1.00 \\
\hline Ground $1.8 \mathrm{~mm}$ & 780 & 35 & 0.2 & $0.13 \pm 0.01$ & 0.12 & $8 \%$ & $<0.3$ & 1.00 \\
\hline Ground $1.8 \mathrm{~mm}$ & 800 & 35 & 0.2 & $0.20 \pm 0.04$ & 0.21 & $5 \%$ & $<0.3$ & 1.00 \\
\hline Ground $0.6 \mathrm{~mm}$ & 850 & 25 & 0.2 & $0.53 \pm 0.01$ & - & - & - & - \\
\hline Ground $3.0 \mathrm{~mm}$ & 850 & 35 & 0.2 & $0.44 \pm 0.05$ & - & - & - & - \\
\hline Ground $1.8 \mathrm{~mm}$ & 950 & 35 & 0.2 & $1.28 \pm 0.92$ & - & - & - & - \\
\hline $0.6 \mathrm{~mm}$ & 850 & 35 & 0.2 & $0.41 \pm 0.03$ & 0.46 & $12 \%$ & 1.6 & 0.57 \\
\hline $1.2 \mathrm{~mm}$ & 770 & 25 & 0.2 & $0.054 \pm 0.005$ & 0.058 & $7 \%$ & 0.8 & 0.84 \\
\hline $1.2 \mathrm{~mm}$ & 870 & 45 & 0.2 & $0.47 \pm 0.33$ & 0.47 & $0 \%$ & 3.4 & 0.29 \\
\hline $1.2 \mathrm{~mm}$ & 850 & 35 & 0.2 & $0.29 \pm 0.02$ & 0.28 & $3 \%$ & 2.8 & 0.35 \\
\hline $1.8 \mathrm{~mm}$ & 750 & 35 & 0.2 & $0.049 \pm 0.010$ & 0.039 & $20 \%$ & 0.7 & 0.86 \\
\hline $1.8 \mathrm{~mm}$ & 780 & 35 & 0.2 & $0.086 \pm 0.017$ & 0.079 & $8 \%$ & 1.2 & 0.69 \\
\hline $1.8 \mathrm{~mm}$ & 800 & 35 & 0.2 & $0.096 \pm 0.020$ & 0.11 & $15 \%$ & 1.7 & 0.55 \\
\hline $1.8 \mathrm{~mm}$ & 850 & 15 & 0.2 & $0.12 \pm 0.01$ & 0.11 & $8 \%$ & 4.3 & 0.23 \\
\hline $1.8 \mathrm{~mm}$ & 850 & $15+4 \% \mathrm{H}_{2}$ & 0.2 & $0.094 \pm 0.001$ & - & - & - & - \\
\hline $1.8 \mathrm{~mm}$ & 850 & 35 & 0.2 & $0.22 \pm 0.02$ & 0.22 & $0 \%$ & 3.8 & 0.27 \\
\hline $1.8 \mathrm{~mm}$ & 850 & 50 & 0.2 & $0.30 \pm 0.17$ & 0.29 & $3 \%$ & 3.5 & 0.28 \\
\hline $1.8 \mathrm{~mm}$ & 900 & 35 & 0.2 & $0.35 \pm 0.04$ & 0.36 & $3 \%$ & 7.8 & 0.1 \\
\hline $1.8 \mathrm{~mm}$ & 950 & 35 & 0.2 & $0.59 \pm 0.18$ & 0.58 & $2 \%$ & 15.2 & 0.07 \\
\hline $1.8 \mathrm{~mm}$ & 950 & 35 & 0.4 & $0.51 \pm 0.3$ & 0.58 & $2 \%$ & 15.2 & 0.07 \\
\hline $1.8 \mathrm{~mm}$ & 950 & $0+21 \% \mathrm{O}_{2}$ & 0.2 & $0.71 \pm 0.01$ & - & - & - & - \\
\hline $1.8 \mathrm{~mm}$ & 950 & $0+21 \% \mathrm{O}_{2}$ & 0.4 & $1.28 \pm 0.19$ & - & - & - & - \\
\hline $2.4 \mathrm{~mm}$ & 850 & 35 & 0.2 & $0.17 \pm 0.11$ & 0.17 & $0 \%$ & 4.8 & 0.21 \\
\hline $2.4 \mathrm{~mm}$ & 930 & 10 & 0.2 & $0.12 \pm 0.05$ & 0.13 & $8 \%$ & 18.8 & 0.05 \\
\hline $3.0 \mathrm{~mm}$ & 850 & 35 & 0.2 & $0.17 \pm 0.01$ & 0.15 & $12 \%$ & 15.2 & 0.07 \\
\hline
\end{tabular}

to determine intrinsic kinetics. The latter was obtained after grinding char particles and sieving the resulting ground sample to a particle size inferior to $250 \mu \mathrm{m}$. Prior to a gasification experiment, the ground char was spread on the crucible surface as a monolayer, in order to minimize the eventual interparticle limitations which can appear in beds with a height above $3 \mathrm{~mm}$ [23].

The overall of the experiments is summarized in Table 3.

No pre-treatment or pre-drying is performed in the char samples. The moisture content was experimentally verified to be quite uniform between different char batches, around $4 \%$ of the total mass.

From the mass loss measured during macro TGA experiments, the conversion $X(t)$ and reactivity $R(t)$ were calculated using Equations (1) and (2) respectively. An average reactivity $R_{\text {ref, }}$, corresponding to the mean value in the conversion range of $20-80 \%$, was selected for each experiment as reference.

$X(t)=\frac{m_{0}-m(t)}{m_{0}}$

$R(t)=\frac{1}{m(t)} \cdot \frac{d m}{d t}$

For each experimental case, the experiment was repeated from 2 to 5 times. The error bar of the reactivity was calculated from the replicates, by applying a t-Student distribution in a $90 \%$ confidence interval.

Special runs in the macro TGA were performed in order to measure the temperature within char particles during gasification. For this, a K-type thermocouple of very thin diameter, $0.25 \mathrm{~mm}$, in order to minimize thermal perturbations, was placed at the centre of the particle, before introduction into the heated zone. This experiment was performed for $1.8 \mathrm{~mm}$ and $2.4 \mathrm{~mm}$ samples, at different reactor temperatures $-840{ }^{\circ} \mathrm{C}$ and $880{ }^{\circ} \mathrm{C}-$, and under a steam mole fraction of $35 \%$ in the atmosphere. No temperature measurements could be performed above $880{ }^{\circ} \mathrm{C}$ because the material of the thermocouple could be damaged.

\subsection{Char characterization}

Char morphology was characterized through the measurement of the bulk density, the apparent density and the specific surface area.

The bulk density was measured using a pycnometer model Micromeritic AccuPyc 1330. The apparent density was calculated by weighing the mass and measuring the particle dimensions to deduce the volume. The specific surface area was measured using a BET analyzer model Micromeritics Tristart II.

From the bulk density $\rho_{\text {bulk }}$ and the apparent density $\rho_{\text {app }}$, it is possible to calculate char porosity $\varepsilon$ from Equation (3). For technical reasons, the pore size distribution could not be obtained in the BET analyzer. Only the mean pore radius $r_{p}$ could be estimated from the porosity, specific surface area $S_{p}$ and apparent density, through Equation (4).

$\varepsilon=1-\frac{\rho_{\text {app }}}{\rho_{\text {bulk }}}$ 
$r_{p}=\frac{4 \cdot \varepsilon}{S_{p} \cdot \rho_{a p p}}$

The bulk density measurements were repeated twice. The apparent density was measured for 15 to 40 particles for each sample group. Similarly to reactivity (Section 2.4), a t-Student distribution was applied to calculate the error bar in a confidence interval of $90 \%$. The error bar of porosity was calculated through the error propagation from the apparent and bulk densities. The specific surface area measurement could only be performed once due to practical reasons. Therefore, the values of specific surface area and mean pore radius are a rough estimation.

The char samples characteristics are displayed in Table 4. It can be seen that the overall of char samples own a predominant macroporous structure $\left(\mathrm{r}_{\mathrm{p}}>50 \mathrm{~nm}\right)$ and have a porosity around $85 \%$. The bulk and apparent densities are similar between the samples.

\section{Model development}

In the FBR model to develop in Gaya project, the gasification model should predict the reaction rate during char conversion as a function of the operating conditions and particle characteristics.

For this, a model based upon the effectiveness factor was selected to model gasification. This approach is classically used to model heterogeneous reactions within a porous catalyst. As it is well known, gasification is a relative slow reaction which occurs within char pores, with similar mechanisms than those from heterogeneous catalysis. This type of model is more suitable to model gasification than surface reaction models, such as the shrinking core model, which are more adapted to fast reactions occurring at the solid surface, like oxidation. Moreover, the selected modelling approach avoids mathematical and computational complexity, which can lead to considerable time saving during its integration into the reactor model.

Some of the expressions from the modelling approach adopted here will consist in empirical coefficients obtained from data fitting, in order to remain the simplest and the most precise possible for the use of the model in the industrial context of the study.

\subsection{General form of the model}

In the effectiveness factor modelling approach, the gasification reaction rate $r_{\text {app }}$ can be calculated by means of Equation (5).

Table 4 - Char characteristics for the $0.6 \mathrm{~mm}, 1.8 \mathrm{~mm}$ and $3.0 \mathrm{~mm}$ char particles.

\begin{tabular}{cccccc} 
Sample & $\begin{array}{c}\rho_{\text {bulk }} \\
\left(\mathrm{kg} \cdot \mathrm{m}^{-3}\right)\end{array}$ & $\begin{array}{c}\rho_{\text {app }} \\
\left(\mathrm{kg} \cdot \mathrm{m}^{-3}\right)\end{array}$ & $\begin{array}{c}\varepsilon \\
(\%)\end{array}$ & $\begin{array}{c}\mathrm{S}_{\mathrm{p}} \\
\left(\mathrm{m}^{2} \cdot \mathrm{g}^{-1}\right)\end{array}$ & $\begin{array}{c}\mathrm{r}_{\mathrm{p}} \\
(\mathrm{nm})\end{array}$ \\
\hline $0.6 \mathrm{~mm}$ & $1592 \pm 297$ & $250 \pm 28$ & $84 \pm 18$ & $\sim 120$ & $\sim 110$ \\
$1.8 \mathrm{~mm}$ & $1712 \pm 130$ & $219 \pm 10$ & $87 \pm 8$ & $\sim 150$ & $\sim 110$ \\
$3.0 \mathrm{~mm}$ & $1676 \pm 282$ & $211 \pm 20$ & $87 \pm 17$ & $\sim 120$ & $\sim 140$ \\
\hline
\end{tabular}

$r_{\text {app }}(X)=\eta \cdot r_{\text {int }} \cdot f(X)$

This modelling approach considers both chemical kinetics with the term $r_{\text {int }}$ and transfer limitations with the effectiveness factor $\eta$. The latter can be written in different ways depending on the limiting transfer phenomena involved and the particle geometry. In the case of reaction rate controlled by chemical kinetics and porous diffusion for isothermal particles, the effectiveness factor can be written in its generalized form as shown in Equation (6). This expression can be employed for $n^{\text {th }}$ order reactions on the condition of using the normalized Thiele modulus $\Phi$, dimensionless number comparing the intrinsic reaction rate $r_{\text {int }}$ and the porous diffusion rate $r_{D}$ as shown in Equation (7).

$\eta=\frac{\tanh (\phi)}{\phi}$

$\phi=\sqrt{\left(\frac{1+n}{2}\right) \cdot \frac{r_{\text {int }}}{r_{D}}}$

The surface function $f(X)$ describes the modification of the reaction rate as a function of conversion.

In the present study, gasification is initially assumed to be controlled by chemical kinetics and porous diffusion, and to occur in an isothermal particle. This implies that external heat and mass transfers are not rate limiting, as well as internal heat transfer. The validity of these assumptions is discussed later in Section 4.

\subsection{Calculation of the characteristic length}

The characteristic length $L c$, defined as the ratio between the particle volume and surface, represents char particle size in the model. The characteristic lengths of the char samples, measured for several particles, are given in Table 2.

An empirical relationship of the characteristic length as a function of thickness $x$ (8) was established through mathematical fitting of the experimental data. The form of this expression is similar to that from an infinite long slab particle of very low thickness: $L_{c}=x / 2$.

$L_{c}=x / 3$

\subsection{Calculation of the intrinsic reaction rate}

The intrinsic reaction rate is expressed as seen in Equation (9). The char molecular weight $M_{\text {char }}$ is supposed to be equivalent to that of carbon: $0.012 \mathrm{~kg} \cdot \mathrm{mol}^{-1}$. This assumption can be justified as char is typically mainly composed of carbon. The apparent density was represented as the average from the values measured for the different char samples (Table 2): $225 \mathrm{~kg} \cdot \mathrm{m}^{-3}$.

$r_{\text {int }}=\frac{k_{\text {int }} \cdot \rho_{\text {app }}}{M_{\text {char }}}$

The chemical kinetics constant $k_{\text {int }}$ follows an Arrhenius law of $n^{\text {th }}$ reaction order with respect to the reagent, here the steam, as shown in Equation (10).

$k_{\text {int }}=k_{0} \cdot \exp (-E a / R \cdot T) \cdot P_{H 2 O}^{n}$ 
The kinetic parameters in this equation $-k_{0}$, Ea, $n$ - were determined from experiments in the macro TGA, performed at low temperatures with ground sample in order to be in a kinetically controlled regime. Three temperatures $-750,780$ and $800{ }^{\circ} \mathrm{C}$ - and three steam mole fractions - 15, 25 and $35 \%$ were tested. It was experimentally verified that the intrinsic reactivity does not differ when changing the char particle size.

The values of the activation energy $E a$, pre-exponential factor $k_{0}$ and of the order of the reaction $n$ were graphically deduced from the measured reactivities using equation (11), by plotting $\ln \left(R_{\text {ref }}\right)$ versus $f\left(\left(T^{-1}\right)\right)$ and $\ln \left(R_{\text {ref }}\right)$ versus $\ln \left(P_{\mathrm{H} 2 \mathrm{O}}\right)$ : $\mathrm{Ea}=275 \mathrm{~kJ} \cdot \mathrm{mol}^{-1} ; k_{0}=7.349 \cdot 10^{7} \mathrm{~s}^{-1} \cdot \mathrm{Pa}^{-0.65} ; n=0.65$.

$\ln \left(R_{\text {ref }}\right)=\ln \left(k_{0}\right)+n \cdot \ln \left(P_{\mathrm{H} 2 \mathrm{O}}\right)-E_{a} / R \cdot T$

In order to verify the absence of transfer limitations in the kinetic parameter determination, additional experiments were performed at $850{ }^{\circ} \mathrm{C}$ and $950{ }^{\circ} \mathrm{C}$ with ground char samples, in an atmosphere of $35 \%$ steam mole fraction. Fig. 2 presents the plot $\ln \left(R_{\text {ref }}\right)$ versus $f\left(\left(T^{-1}\right)\right)$ in the range $750-950{ }^{\circ} \mathrm{C}$. It was found that for temperatures above $800{ }^{\circ} \mathrm{C}$, the activation energy decreases from 275 to $135 \mathrm{~kJ} \cdot \mathrm{mol}^{-1}$, which reflects a regime change. The high value of the activation energy between $750{ }^{\circ} \mathrm{C}$ and $800{ }^{\circ} \mathrm{C}$ suggests that ground char gasification occurs in a kinetically controlled regime below $800{ }^{\circ} \mathrm{C}$. Above this temperature, the decrease of the activation energy may suggest that transfers become limiting.

\subsection{Calculation of the diffusion rate}

The diffusion rate is classically expressed as shown in Equation (12). The steam concentration $\mathrm{C}_{\mathrm{H} 2 \mathrm{O}}$ corresponds to the concentration on char external surface which is the same as that found in the reactor, as external mass transfers are assumed not limiting.

$r_{D}=\frac{D}{L_{C}^{2}} \cdot C_{H 2 O}$

The steam concentration $\mathrm{C}_{\mathrm{H} 2 \mathrm{O}}$ can then be expressed by means of temperature $T$ and steam partial pressure $P_{\mathrm{H} 2 \mathrm{O}}$ through the perfect gas law, as displayed in Equation (13).

$\mathrm{C}_{\mathrm{H} 2 \mathrm{O}}=\frac{P_{\mathrm{H} 2 \mathrm{O}}}{R \cdot T}$

In this model, the diffusion coefficient $D$ was represented

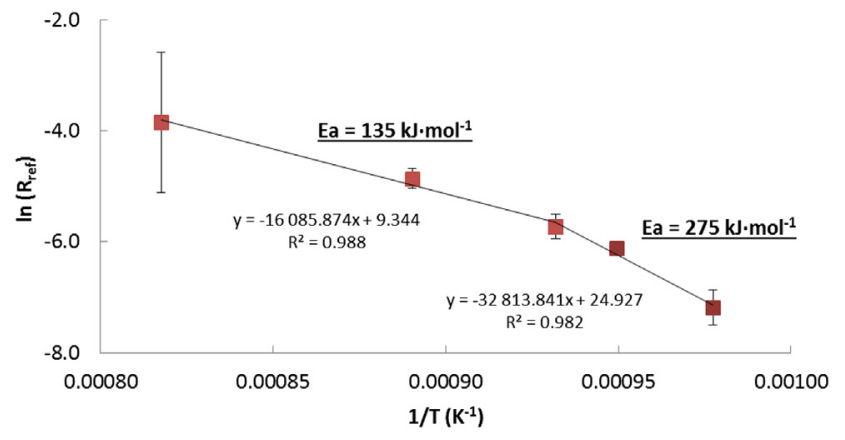

Fig. 2 - Logarithm of reactivity versus the inverse of temperature in the range $7500^{\circ} \mathrm{C}-9500^{\circ} \mathrm{C}$. by an empirical expression (14), which was developed through mathematical fitting of the values obtained so that the apparent reactivity calculated from the model matches to that experimentally measured. The experiments used for this propose were the gasification of $3 \mathrm{~mm}$ char samples at $780^{\circ} \mathrm{C}$, $800^{\circ} \mathrm{C}, 850^{\circ} \mathrm{C}, 900^{\circ} \mathrm{C}$ and $950^{\circ} \mathrm{C}$.

$\mathrm{D}=2.53 \cdot 10^{11} \cdot \mathrm{T}^{-3.8}$

The diffusion coefficient calculated from Equation (14) is in the order of $10^{-6} \mathrm{~m}^{2} \cdot \mathrm{s}^{-1}$ in the temperature range of $750{ }^{\circ} \mathrm{C}-950{ }^{\circ} \mathrm{C}$. This value is considerably lower than that could be expected after theoretical calculations, in the order of $10^{-5} \mathrm{~m}^{2} \cdot \mathrm{s}^{-1}$ (refer to Appendix). This difference suggests that supplementary phenomena, apart from porous steam diffusion, could be included in the diffusion coefficient. These phenomena would also explain the atypical trend of the diffusion coefficient with temperature. In fact, the diffusion coefficient theoretically increases by increasing temperature, on the contrary to the trend observed in Equation (14).

In the present model, the diffusion coefficient will be then considered as a global function which includes porous steam diffusion and supplementary phenomena. In Section 4, assumptions about possible causes of the supplementary rate limiting phenomena will be provided.

\subsection{Calculation of the surface function}

During gasification, modifications in the char solid matrix occur and affect the reaction rate due to variations of concentration and reactivity of the reactive sites. These modifications are very difficult to characterize and so their modelling can be very complex. Therefore, a surface function is usually used to implicitly describe the reactive surface evolution during the transformation. The experimental surface function can be obtained by the ratio of reactivity at a given conversion with respect to the reference reactivity, $f(X)=R(X) / R_{\text {ref. }}$.

Fig. 3 shows the experimental surface functions obtained until $80 \%$ of conversion for several experimental cases. Beyond $80 \%$ of conversion, the surface functions are not reliable, because of the high uncertainty in the sample mass at the final stage of the transformation.

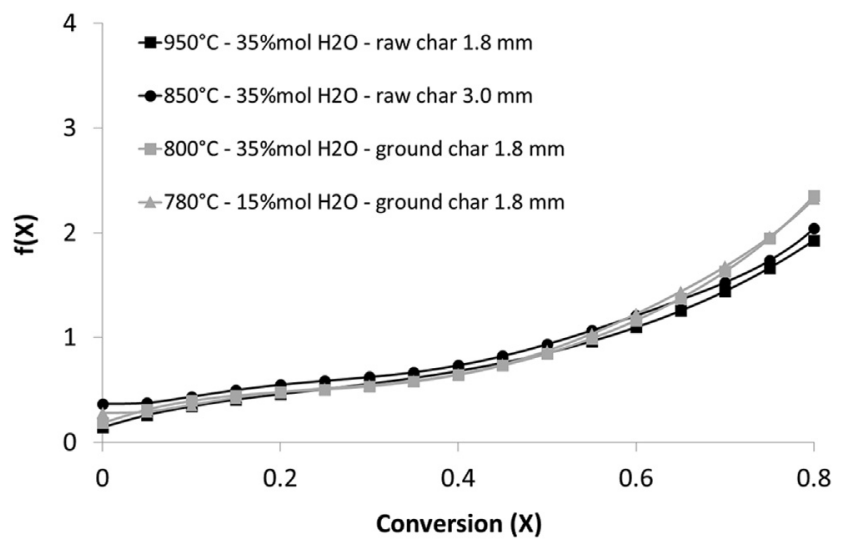

Fig. 3 - Surface function calculated from for different experimental cases. 
It can be seen that the surface functions globally increase with conversion, which implies a reactivity increase as the reaction proceeds. In the case of biomass, this is classically explained by a reactive surface growth during the transformation and by the increase of inorganic matter concentration, which leads to a higher catalytic activity [25].

The surface functions from Fig. 3 are very close one to each other. This same trend was observed for all other experimental cases, not represented here. Therefore, the profile of the surface function during conversion seems to be independent from the particle size and the operating conditions. The same surface function can be then applied whatever the experimental case. Different kind of surface function models, based on physical or empirical concepts, exist in literature. To remain the simplest and the most precise possible in the present model, an empirical fitting $6^{\text {th }}$ degree polynomial (15) was selected to represent the surface function, as frequently done in literature $[5,14,26]$.

$$
\begin{aligned}
f(X)= & 34.228 X^{6}-69.460 X^{5}+49.267 X^{4}-7.903 X^{3}-2.653 X^{2} \\
& +1.633 X+0.345
\end{aligned}
$$

\section{Results and discussion}

In this section, the experimental findings, on which the model is based, will be presented and discussed. Afterwards, the model accuracy will be tested by comparing its results with the experiments, and its pertinence with respect to models from literature will be discussed.

\subsection{Experimental characterization of steam char gasification}

4.1.1. Effect of temperature, atmosphere composition, gas velocity and particle size

Fig. 4 presents the effect of temperature (a), atmosphere composition (b), gas velocity (c) and particle size (d), on char reactivity. Generally, reactivity is higher by increasing the temperature and steam concentration in the atmosphere, and by decreasing particle size. Gas velocity does not show any considerable effect on reactivity. Moreover, the addition of $\mathrm{H}_{2}$ in the atmosphere leads to a slight decrease of reactivity.

The considerable increase of reactivity with increasing temperature suggests that chemical kinetics influences char gasification (Fig. 4a). Nevertheless, the low apparent activation energy measured from these experiments, $16 \mathrm{~kJ} \cdot \mathrm{mol}^{-1}$, shows limitation by transfers. This is confirmed in Fig. $4 \mathrm{~d}$ where char reactivity decreases with increasing particle size following a raised -0.6 power law with respect to thickness. This result is close to the findings from Standish et al. [16], which observe a power law relation between particle size and reactivity raised to power -0.8 .

Char reactivity depends on steam concentration, which has a positive influence in both chemical and transfer phenomena. In Fig. $4 \mathrm{~b}$, the apparent order of the reaction is about 0.8 , which is intermediary between the values from a kinetically controlled regime - order 0.64 - and a regime only controlled by transfers - order 1 .
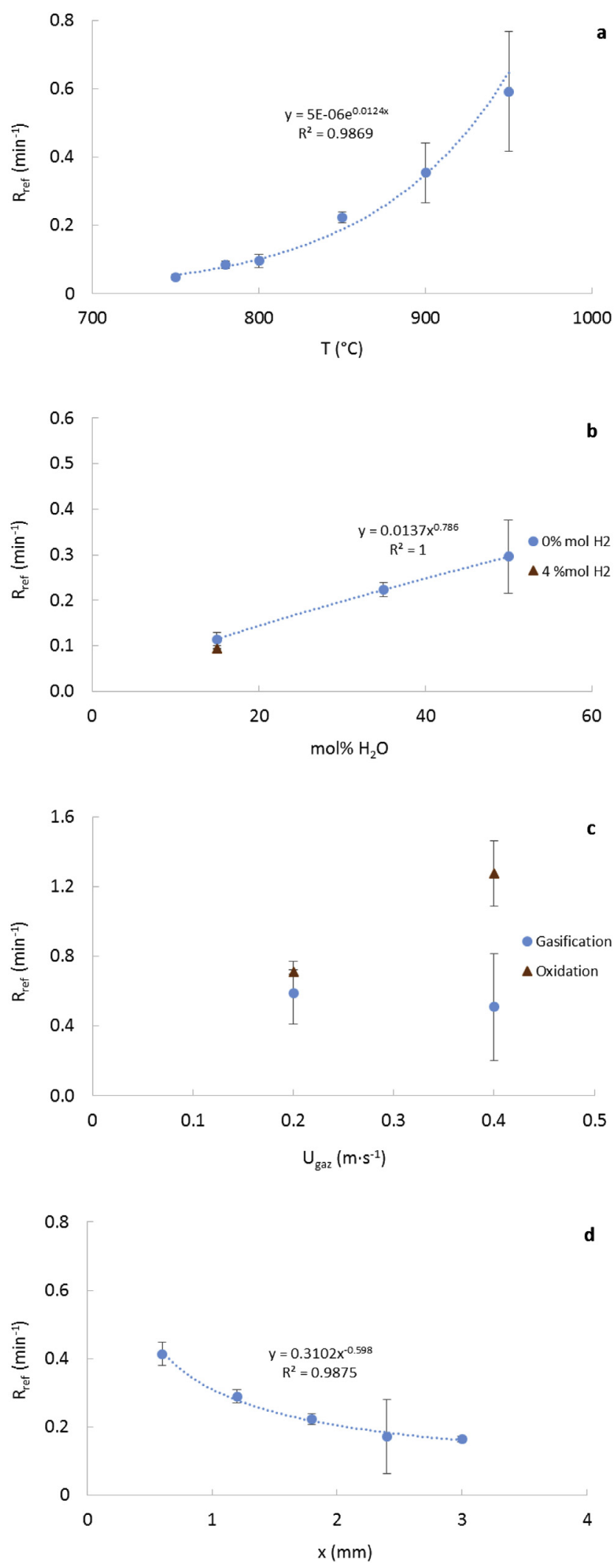

Fig. 4 - Reference reactivity measured in macro TGA experiments versus temperature (a), atmosphere composition (b), gas velocity (c) and particle size (d). The references conditions are: $850{ }^{\circ} \mathrm{C}$, steam molar fraction of $35 \%$ in the atmosphere, gas velocity $0.2 \mathrm{~m} \cdot \mathrm{s}^{-1}, 1.8 \mathrm{~mm}$ sample. 
Table 5 - Temperature measured within the $1.8 \mathrm{~mm}$ and $2.4 \mathrm{~mm}$ samples, during gasification experiments at $840{ }^{\circ} \mathrm{C}$ and $880{ }^{\circ} \mathrm{C}$, in an atmosphere of $35 \%$ steam molar fraction.

\begin{tabular}{cccc} 
Sample & $\begin{array}{c}\text { Reactor temperature } \\
\left({ }^{\circ} \mathrm{C}\right)\end{array}$ & $\begin{array}{c}\text { Particle temperature before } \\
\text { gasification }\left({ }^{\circ} \mathrm{C}\right)\end{array}$ & $\begin{array}{c}\text { Minimum particle temperature } \\
\text { during gasification }\left({ }^{\circ} \mathrm{C}\right)\end{array}$ \\
\hline $1.8 \mathrm{~mm}$ & 840 & 836 & 834 \\
& 880 & 876 & 868 \\
$2.4 \mathrm{~mm}$ & 840 & 836 & 825 \\
& 880 & 874 & 860 \\
\hline
\end{tabular}

In Fig. 4c, the steam gasification reactivities for the two gas velocities are very close. It can be then assumed that external transfers are not rate limiting. As these experiments were performed under the experimental conditions more propitious to external transfer limitations, i.e. at the highest temperature $-950{ }^{\circ} \mathrm{C}$-, the neglecting effect of external mass transfer has to be the same at lower temperatures. In order to test the reaction rate sensibility with respect to the gas velocity in the macro TGA, experiments were performed in a known situation where reaction rate is strongly controlled by external mass transfers, namely char oxidation. In this case, which is also presented in Fig. 4c, a reactivity increase with increasing gas velocity could be clearly observed.

Fig. $4 \mathrm{c}$ shows that the presence of $\mathrm{H}_{2}$ in the gasification atmosphere has a negative impact on reactivity. As it is well known, $\mathrm{H}_{2}$ can induce to gasification inhibition. This can occur at low $\mathrm{H}_{2}$ concentration and atmospheric pressure according to the present work, and could then be one of the rate limiting phenomena included in the diffusion coefficient from the model (refer to Section 3.4). As stated by Gomez-Barea et al. [2], the gasification products $-\mathrm{H}_{2}$ and $\mathrm{CO}-$ during its diffusion out of the particle may influence the reaction rate. For future works, the contribution of $\mathrm{H}_{2}$ inhibition on the gasification reaction rate could be implicitly included in the model, for example by Langmuir-Hinshelwood type chemical kinetics.

\subsubsection{Temperature evolution within char particles}

As gasification is an endothermic reaction, a temperature gradient can appear inside the particle. If this is the case, temperature is lower inside the particle than at its surface during the transformation, which can lead to the decrease of the global reaction rate. If internal heat transfer is fast enough, the particle remains isothermal during the transformation. Table 5 shows the temperatures measured within the $1.8 \mathrm{~mm}$ and $2.4 \mathrm{~mm}$ char particles during gasification experiments at $840^{\circ} \mathrm{C}$ and $880^{\circ} \mathrm{C}$, under an atmosphere of $35 \%$ steam mole fraction.

During gasification, the particle temperature decreases of some ${ }^{\circ} \mathrm{C}$ for both samples. The maximum temperature decrease measured for each case was: $2{ }^{\circ} \mathrm{C}$ and $11{ }^{\circ} \mathrm{C}$ for respectively $1.8 \mathrm{~mm}$ and $2.4 \mathrm{~mm}$ samples at $840{ }^{\circ} \mathrm{C} ; 8^{\circ} \mathrm{C}$ and $14^{\circ} \mathrm{C}$ for respectively $1.8 \mathrm{~mm}$ and $2.4 \mathrm{~mm}$ samples at $880^{\circ} \mathrm{C}$. Therefore, the transformation in this study cannot be rigorously considered as isothermal. The assumption of isothermal transformation for the model is then only an approximation, which can be valid for small particles and relative low temperatures. In the studied cases from this section, gasification could only be approximated as isothermal for the gasification of $1.8 \mathrm{~mm}$ sample at $840{ }^{\circ} \mathrm{C}$.
At the higher temperatures, it could be possible that the decrease of temperature within the particles leads to a decrease of the global reaction rate, particularly for large particles. In these conditions, the decrease of reaction rate by the endothermic character of gasification could be another of
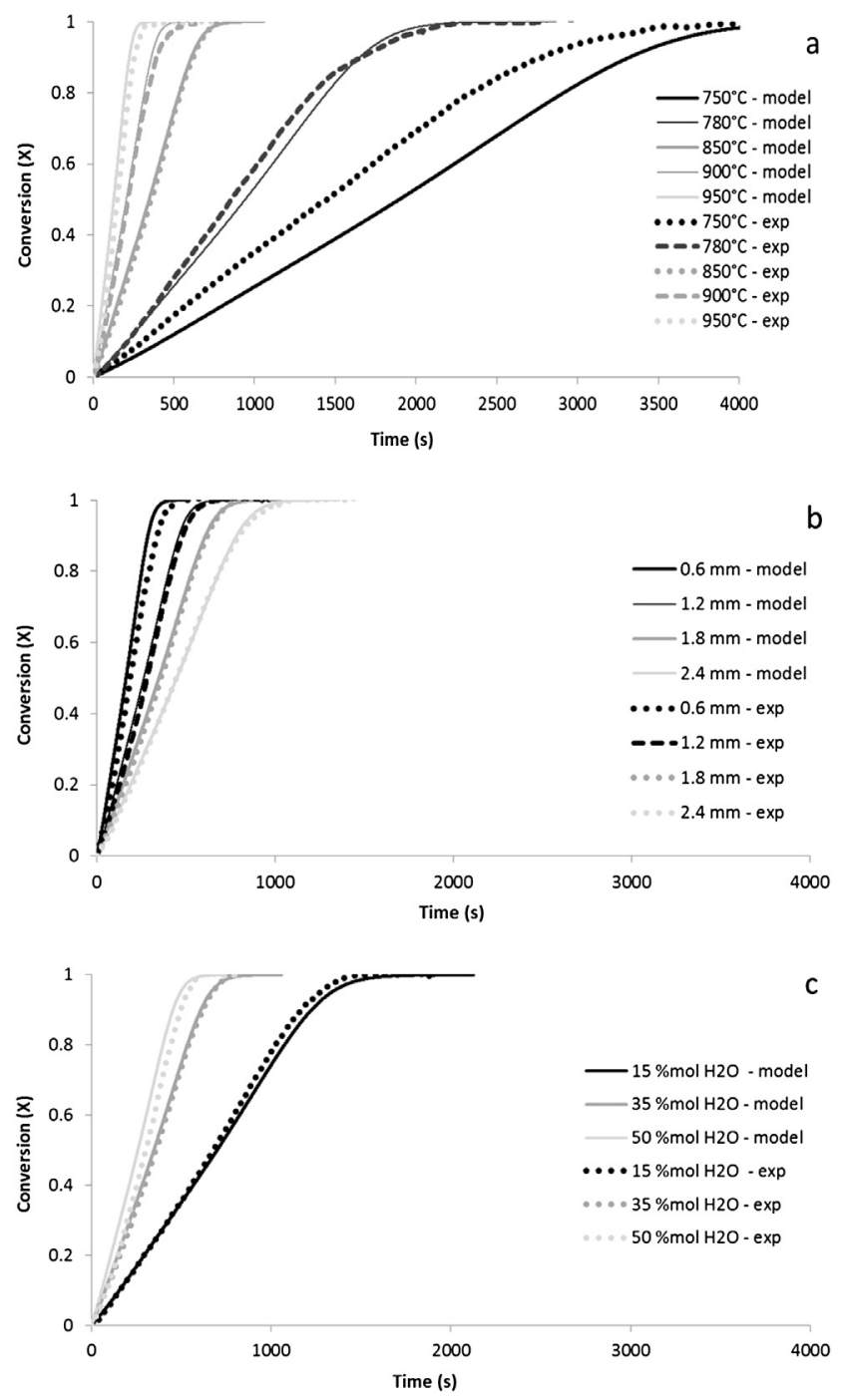

Fig. 5 - Experimental and modelling conversion rate during the gasification of: (a) $1.8 \mathrm{~mm}$ particles at different temperatures, in an atmosphere of $35 \%$ steam molar fraction; (b) different particle sizes at $850{ }^{\circ} \mathrm{C}$ in an atmosphere of $35 \%$ steam molar fraction; (c) $1.8 \mathrm{~mm}$ particles at $850^{\circ} \mathrm{C}$, under different steam concentrations in the atmosphere. 
the rate limiting phenomena included in the diffusion coefficient from the model (refer to Section 3.4).

\subsection{Results from the steam char gasification modelling}

Fig. 5 displays the experimental and predicted conversion profile obtained during char particles gasification as a function of temperature (a), particle size (b) and steam concentration (c). Note that the experimental results as a function of temperature (Fig. 5a) are directly involved in the development of the model, which is not the case for those as a function of particle size (Fig. 5b) and steam concentration (Fig. 5c).

It can be seen that the modelling results are, globally, in good agreement with the experimental data.

In Fig. 6 , the model was confronted to additional experimental cases which were selected randomly and were not used for the model development. It can be seen that the model gives also accurate predictions.

The reactivities, as the Thiele moduli and efficiences computed from the model, for the overall of the experiments are displayed in Table 3. It can be seen that the overall of experimental cases are spread in a wide range of efficiencies and Thiele moduli. The deviation between the experimental and modelling reactivities is within the error bar and is globally lower than $10 \%$. Some cases exceed this value, but never go beyond a deviation of $20 \%$. This confirms the reliable predictions of the model in the conditions of interest.

Compared to the model developed in the present work, volumetric and structural models (refer to Section 1) can provide more detailed information about the transformation during gasification, such as: local conversions; temperature, gas concentration, pressure gradients with the particle; variations in the reactive surface; local variations of the diffusive and convective permeability parameters; local evolution of porosity; etc ... However, these type of models present too much complexity with respect to the fixed industrial purpose.

The model proposed by Gomez-Barea et al. [14] adopted the effectiveness factor approach, as in this work, to model

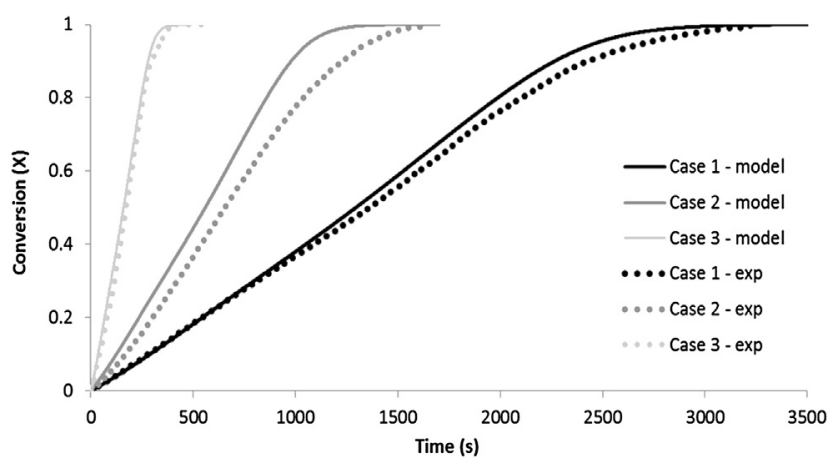

Fig. 6 - Experimental and modelling conversion rate of different experimental cases (Case 1: $770{ }^{\circ} \mathrm{C}, 25 \%$ steam molar fraction, $1.2 \mathrm{~mm}$ sample; Case2: $930{ }^{\circ} \mathrm{C}, 10 \%$ steam molar fraction, $2.4 \mathrm{~mm}$ sample; Case 3: $870{ }^{\circ} \mathrm{C}$, $45 \%$ steam molar fraction, $1.2 \mathrm{~mm}$ sample). spherical char particles gasification with $\mathrm{CO}_{2}$. In comparison to the present study, it provides a better description of gasification, by clearly describing the individual contributions of the chemical kinetics, porous diffusion, internal heat transfers and external transfers on reaction rate. Nonetheless, the model from the present work is approached in a simpler way, with the same accuracy than from GomezBarea et al. [14].

The model developed by Teixeira et al. [17] was successfully validated for char from woodchips pyrolysis. This original approach is simpler than that presented in this work, however it is purely empirical, based on mathematical fitting of the experimental data.

\section{Conclusions}

A semi-empirical model was developed from thermogravimetric experiments. Under the explored conditions, gasification of char from woodchips fast pyrolysis is controlled by chemical kinetics and internal transfer phenomena. The external transfers show to be not rate limiting. Gasification has been verified to be isothermal only under certain conditions, more likely at low temperature and particle size.

The diffusion coefficient in the model, obtained from experimental data fitting, is suspected to probably include supplementary rate limiting phenomena, apart from steam porous diffusion. In particular, the diffusion coefficient could include the inhibition by the product $\mathrm{H}_{2}$ while diffusing out of the particle. Gasification experiments by adding a few mole fractions of $\mathrm{H}_{2}$ in the atmosphere show that $\mathrm{H}_{2}$ inhibition is possible even at low concentrations. Another rate limiting phenomenon could be the decrease of temperature within the particle during gasification due to the endothermic character of the reaction, leading to a decrease of chemical kinetics. Temperature measurements within char particles show that gasification at relative high temperatures can lead to a considerable decrease of char temperature particularly by increasing particle size. Under these conditions, the transformation cannot be considered anymore as isothermal.

The gasification model predicts with accuracy the experimental results in the operating conditions of an FBR. For its simplicity and reliability in the conditions of interest, this approach is suitable to be used for the description of char gasification into a FBR model.

\section{Acknowledgements}

The authors would like to acknowledge the ADEME (Grant number is 0901C0124) for its financial support and all the collaborators from GAYA project, in particular the members from the CEA, CIRAD, LRGP, LGP and GDF - SUEZ. We also thank the invaluable support of the technical staff at the 'Ecole des Mines d'Albi', especially Mr. Bernard AUDUC, Mr. Denis MARTY and Mrs. Celine Boachon, as the PhD student Pierre-Marie Nigay for its experimental help. 


\section{Appendix}

Diffusion in a porous solid is usually considered to be controlled by both molecular and Knusden diffusion, which can be calculated through Equations (A1) and (A2) respectively. The global diffusion coefficient depends on the solid internal morphology, namely porosity and tortuosity, and on the inverse sum of the diffusive resistances, as shown in Equation (A3).

$D_{m}=\frac{10^{-7} \times T^{1.75} \times\left(\frac{1}{M_{\mathrm{H} 20}}+\frac{1}{M_{\mathrm{N} 2}}\right)^{0.5}}{P_{\mathrm{t}} \times\left(\left(\sum \gamma\right)_{\mathrm{H} 2 \mathrm{O}}^{1 / 3}+\left(\sum \gamma\right)_{\mathrm{N} 2}^{1 / 3}\right)^{2}}$

$D_{k}=\frac{2}{3} \times r_{p} \times \sqrt{\frac{2 \times R \times T}{\pi \times M_{\text {char }}}}$

$D=\frac{\varepsilon}{\tau} \times \frac{1}{\frac{1}{D_{m}}+\frac{1}{D_{k}}}$

The molecular weights used in Equations (A1) and (A2) are: $M_{\text {char }}=0.012 \mathrm{~kg} \cdot \mathrm{mol}^{-1}$ (same molecular weight than carbon); $M_{\mathrm{H} 2 \mathrm{O}}=0.018 \mathrm{~kg} \cdot \mathrm{mol}^{-1} ; \mathrm{M}_{\mathrm{N} 2}=0.028 \mathrm{~kg} \cdot \mathrm{mol}^{-1}$. The diffusion volumes employed in Equation (A1) are: $(\Sigma r)_{\mathrm{H} 2 \mathrm{O}}=12.7 ;(\Sigma r)_{\mathrm{H} 2 \mathrm{O}}=17.9$. The mean porous radius $r_{p}$ estimated from experiments (Table 4) was used for the determination of Knudsen coefficient diffusion (A2). The tortuosity could not be directly measured, and the typical value of the ratio $\varepsilon / \tau$ proposed in literature for char from biomass -0.15 [9] -, was used for the calculation of the global diffusion coefficient (A3).

From the calculations above, the diffusion coefficient is estimated to be in the order of $10^{-5} \mathrm{~m}^{2} \cdot \mathrm{s}^{-1}$ for the different char samples in the temperature range of $800^{\circ} \mathrm{C}-950^{\circ} \mathrm{C}$.

\section{R E F E R E N C E S}

[1] Noubli H, Valin S, Spindler B, Hemati M. Development of a modelling tool representing biomass gasification step in a dual fluidized bed. Can J Chem Eng 2015;93(2):340-7.

[2] Gómez-Barea A, Ollero P, Fernández-Baco C. Diffusional effects in $\mathrm{CO} 2$ gasification experiments with single biomass char particles. 1. Experimental investigation. Energy Fuels 2006;20(5):2202-10.

[3] Mani T, Mahinpey N, Murugan P. Reaction kinetics and mass transfer studies of biomass char gasification with CO2. Chem Eng Sci 2011;66(1):36-41.

[4] Hawley MC, Boyd M, Anderson C, DeVera A. Gasification of wood char and effects of intraparticle transport. Fuel 1983;62(2):213-6.

[5] Van de steene L, Tagutchou JP, Escudero Sanz FJ, Salvador S. Gasification of woodchip particles: experimental and numerical study of char-H2O, char-CO2, and char-O2 reactions. Chem Eng Sci 2011;66(20):4499-509.

[6] Heesink ABM, Prins W, van Swaaij WPM. A grain size distribution model for non-catalytic gas-solid reactions. Chem Eng J Biochem Eng J 1993;53(1):25-37.
[7] Bhatia SK, Perlmutter DD. A random pore model for fluidsolid reactions: II. Diffusion and transport effects. AIChE J 1981;27(2):247-54.

[8] Bhatia SK, Perlmutter DD. A random pore model for fluidsolid reactions: I. Isothermal, kinetic control. AIChE J 1980;26(3):379-86.

[9] Groeneveld MJ, van Swaaij WPM. Gasification of char particles with $\mathrm{CO} 2$ and $\mathrm{H} 2 \mathrm{O}$. Chem Eng Sci 1980;35(1-2):307-13.

[10] Singer SL, Ghoniem AF. Comprehensive gasification modeling of char particles with multi-modal pore structures. Combust Flame 2013;160(1):120-37.

[11] Brem G, Brouwers JJH. Analytical solutions for non-linear conversion of a porous solid particle in a gas - I. Isothermal conversion. Chem Eng Sci 1990;45(7):1905-13.

[12] Brem G, Brouwers JJH. Analytical solutions for non-linear conversion of a porous solid particle in a gas - II. Nonisothermal conversion and numerical verification. Chem Eng Sci 1990;45(7):1915-24.

[13] Gómez-Barea A, Ollero P. An approximate method for solving gas-solid non-catalytic reactions. Chem Eng Sci 2006;61(11):3725-35.

[14] Gómez-Barea A, Ollero P, Villanueva A. Diffusional effects in CO2 gasification experiments with single biomass char particles. 2. Theoretical predictions. Energy \& Fuels 2006;20(5):2211-22.

[15] Mermoud F, Golfier F, Salvador S, Van de Steene L, Dirion JL. Experimental and numerical study of steam gasification of a single charcoal particle. Combust Flame 2006;145(1-2):59-79.

[16] Standish N, Tanjung AF. Gasification of single wood charcoal particles in CO2. Fuel 1988;67(5):666-72.

[17] Teixeira G, Van de steene L, Ponthieux A, Salvador S. Prediction of the gasification kinetics of a single wood char particle from a limited set of parameters. Fuel 2014;123:194-204.

[18] Gómez-Barea A. Modelling of diffusional effects during the gasification of biomass char particles in a fluidized-bed [PhD thesis]. Spain: Universidad de Sevilla; 2006.

[19] Kramb J, Konttinen J, Gómez-Barea A, Moilanen A, Umeki K. Modeling biomass char gasification kinetics for improving prediction of carbon conversion in a fluidized bed gasifier. Fuel 2014;132:107-15.

[20] Agarwal PK. Transport phenomenain multi-particles systems. IV, Heat transfer to a large freely moving particle in gas fluidized bed of smaller particles. Chem Eng Sci 1991;46(4):1115-27.

[21] Dyrness A, Glicksman LR, Yule T. Heat transfer in the splash zone of a bubbling fluidized bed. Int J Heat Mass Transf 1992;35(4):847-60.

[22] Oka SN. Fluidized bed combustion - Chapter 3. Heat and mass transfer in fluidized beds. In: Anthony EJ, editor. Fluid. bed combust. New York: Marcel Dekker; 2004. p. 147-210.

[23] Ollero P, Serrera A, Arjona R, Alcantarilla S. Diffusional effects in TGA gasification experiments for kinetic determination. Fuel 2002;81(15):1989-2000.

[24] Guizani C, Escudero Sanz FJ, Salvador S. Effects of CO2 on biomass fast pyrolysis: reaction rate, gas yields and char reactive properties. Fuel 2014;116:310-20.

[25] Zhang Y, Ashizawa M, Kajitani S, Miura K. Proposal of a semi-empirical kinetic model to reconcile with gasification reactivity profiles of biomass chars. Fuel 2008;87(4-5):475-81.

[26] Guizani C, Escudero Sanz FJ, Salvador S. The gasification reactivity of high-heating-rate chars in single and mixed atmospheres of $\mathrm{H}_{2} \mathrm{O}$ and $\mathrm{CO}_{2}$. Fuel 2013;108:812-23. 